DEPÓSITO LEGAL ZU2020000153

Esta publicación científica en formato digital

es continuidad de la revista impresa

ISSN 0041-8811

E-ISSN 2665-0428

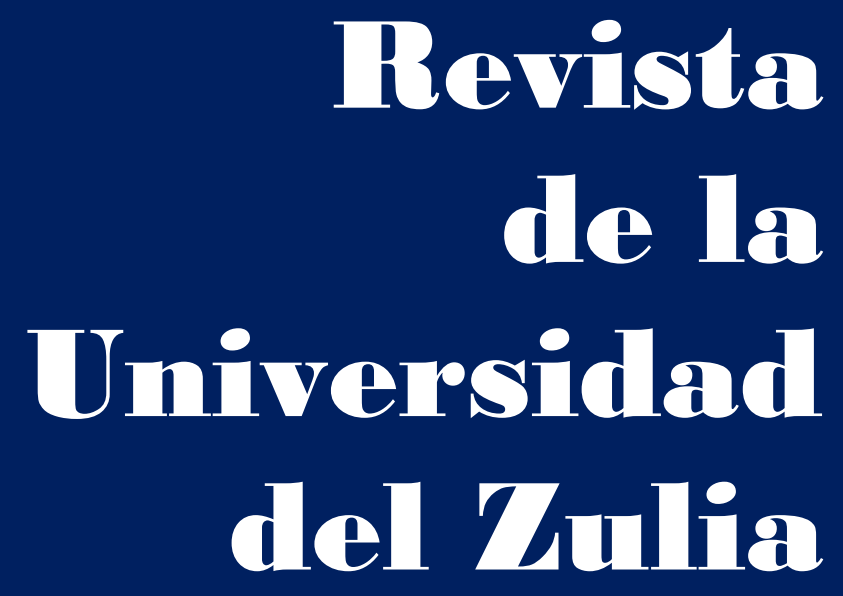

Fundada en 1947

por el Dr. Jesús Emrique Lossada

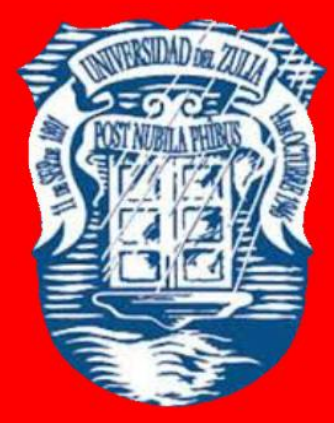

Ciencias

Sociales

y Arte

Año $12 \quad N^{\circ} 34$

Septiembre - Diciembre 2021

Tercera Época

Maracaibo-Veneruela 


\section{Social policy of Russia and China: a comparative analysis of approaches to working with the elderly population}

\section{Li Zhongyuan *}

ABSTRACT

Objective. This article compares the approaches in social policy in relation to the elderly population of Russia and China, a relevant topic, since both countries at the end of the twentieth century faced the problem of population aging. At the same time, the principles of working with older people in these countries have a number of similarities and significant differences that have the potential to strengthen the exchange of experiences. method. Interviews with specialists in the field of the application of social policy in this area. The interview guide consists of three blocks, the third of which is specialized for respondents by country. Block 1 (7 questions) aims at a general assessment of the situation of the elderly population in the country from the point of view of the perception of the elderly as a social group, their role in society, as well as a general description of social policy in this area. Block 2 (4 questions) aims at a more detailed discussion of the problems of social policy in relation to the elderly population from the point of view of various socio-cultural groups. Block 3 (1 general and 3 special questions) is a list of social policy measures in the field of population ageing, which is offered to the expert for evaluation. Since the study aims to find ways to adapt and borrow social policy measures for each country, respondents from China will be offered Russian measures, and respondents from Russia, Chinese measures. results. The interviews conducted demonstrate the relevance of a possible exchange of experiences between countries and enabled us to identify the areas in which such an exchange will be most effective.

KEYWORDS: social policy; management sociology; ageing population; Culture; population decrease; population problems.

* Aspirant. Department of Sociology; Moscow State Institute of International Relations (University) of the Ministry of Foreign Affairs of Russia. Department of Sociology, specialty:22.00.08 sociology of management. ORCID: https://orcid.org/0000-0002-3643-7402. E-mail:nzm8628@mail.ru 


\section{Política social de Rusia y China: un análisis comparativo de enfoques para trabajar con la población de edad avanzada}

RESUMEN

Objetivo. Este artículo compara los enfoques en la política social en relación con la población anciana de Rusia y China, tema relevante, ya que ambos países a finales del siglo XX se enfrentaron al problema del envejecimiento de la población. Al mismo tiempo, los principios de trabajar con las personas mayores en estos países tienen una serie de similitudes y diferencias significativas que tienen el potencial de reforzar el intercambio de experiencias. Método. Entrevistas a especialistas en el campo de la aplicación de la política social en esta área. La guía de entrevistas consta de tres bloques, el tercero de los cuales está especializado para los encuestados por país. El bloque 1 (7 preguntas) tiene por objeto una evaluación general de la situación de la población anciana en el país desde el punto de vista de la percepción de las personas mayores como grupo social, su papel en la sociedad, así como una descripción general de la política social en este ámbito. El bloque 2 ( 4 preguntas) tiene por objeto un debate más detallado de los problemas de la política social en relación con la población de edad avanzada desde el punto de vista de diversos grupos socio-culturales. El bloque 3 (1 general y 3 preguntas especiales) es una lista de medidas de política social en el ámbito del envejecimiento de la población, que se ofrece al experto para su evaluación. Dado que el estudio tiene como objetivo encontrar formas de adaptar y tomar prestadas medidas de política social para cada país, a los encuestados de China se les ofrecerán medidas rusas, y a los encuestados de Rusia, medidas chinas. Resultados. Las entrevistas realizadas demuestran la pertinencia de un posible intercambio de experiencias entre países y nos permitieron identificar las áreas en las que dicho intercambio será más eficaz.

PALABRAS CLAVE: política social; sociología de la gestión; envejecimiento de la población; Cultura; disminución de la población; problemas de población.

\section{Introduction}

The global trend of increasing the share of the elderly population in the demographic structure is a challenge for most countries of the world, including Russia and China. Population ageing can be both a threat (Dobrokhleb, 2017), and an opportunity (Ntugarten, 2016), which makes cross-country comparative studies particularly relevant from a managerial perspective. An increase in the effectiveness of public policies on population ageing, while addressing their cultural context, can be achieved through the exchange of experience with other countries, which will help to find alternative solutions to the policy objectives. Solving 
REVISTA DE LA UNIVERSIDAD DEL ZULIA. 3ª época. Año $12 \mathrm{~N}^{\circ}$ 34, 2021

Li Zhongyuan // Social policy of Russia and China: a comparative analysis... 282-296

DOI: http://dx.doi.org/10.46925//rdluz.34.17

the problems of an aging society is a multi-faceted task. When considering such a large-scale issue, it could be useful to attract foreign experience. To test this assumption, the author conducted interviews with Russian and Chinese experts and practitioners in the field of social policy.

1. On the main theoretical approaches to solving the problems of population aging Today, approaches to finding possible solutions to the problems of an aging society can be divided into three groups: the statistical-economic, approach, the distance/stratification approach, and the symbolic approach.

From a statistical point of view, Russia faced the issue of population aging earlier, than in China. Already in 1995, Russia adopted the law "On State Benefits for citizens, with children", which aims to provide material support for motherhood, fatherhood and childhood according to the Law of the Russian Federation № 81-FZ, 1995, and, as a result, shift the gender and age pyramid towards the working-age population by increasing the number of children. In China, changes appeared later, under the influence of the demographic policy "onechild policy", which was in force since the 70s of the 20th century: only from 2016, the Chinese are allowed to have two children. Initially, this policy was introduced to reduce the birth rate in the country. However, its unintended consequence was an increase in the share of the elderly in the structure of the country's population.

According to UN statistics, the share of the population over 65 in Russia increased to $7 \%$ in the 70 s of the last century, and in China a similar percentage of the elderly has been observed only since the 2000s base on the World Population Prospects in 2017. Dynamics in both countries are directed towards increasing the proportion of the aged, and a variety of options are being considered to work with this. There are "simple " methods of changing the age balance of the population, for example, simplifying the regime of work and residence in the country for migrants. However, such a strategy is not applicable either in Russia, or in China, primarily due to the emerging shortage of resources, material and social (Fadeeva, 2018). The experience of applying such a strategy has demonstrated the emergence of a number of related problems: for example, due-to the influx of migrants in Russia, the problem of choosing employees based on appearance criteria has become more acute (Zayonchkovskaya, Mkrtchyan, 2007). In China, the influx of migrants mainly introduced in the chapels of the 


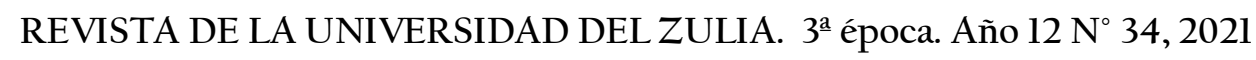

Li Zhongyuan // Social policy of Russia and China: a comparative analysis... 282-296

DOI: http://dx.doi.org/10.46925//rdluz.34.17

country's territory, has led to an imbalance in the number and demographic structure of the population by region. Another consequence of the opening of the labor market in China was an increase in the total population, which put a strain on all social systems, and, as a result, caused the need to raise the retirement age and improve the legal system to protect the rights of older citizens (Guo, 2007).

The statistical-and economic approach to the analysis of old age includes an analysis of the degree of economic activity of this population group. It is assumed, that economic activity can be the result of both generating resources for the employer, and through simple consumer behavior, which remains the only option for an elderly person outside the labor market. However, stimulating economic activity through the payment of pensions leads to budget deficits, and the implementation of effective strategies requires paying more attention to the role of the state as the main managing entity in the country, rationally allocating resources. At the moment, the effectiveness of pension systems is not sufficient, to become the most significant element of social policy and research in this area; moreover, the structure of pension systems is highly dependent not on the existing needs of the elderly, but on the culture and history of the country (Galasso, Profeta, 2018).

The second approach to finding solutions to the problems of population aging is a set of positions, according to which it is necessary to reduce the distance between the elderly and young populations, help provide material and psychological support to older generations, and, on the other hand, stimulate the exchange of information between generations in a prefigurativeo-culturalsociety.

This is the essence of the "active aging" principle." -- The main international guiding principle on working with older persons in the twenty-first century as said "Report of the World Assembly on Ageing(1982)", adopted by the United Nations during the Second World Assembly on Ageing in Madrid in April 2002 2002. In the second chapter, "Recommendations for action", the first item of the priority area is formulated as" participation of older people in development", which confirms the need to represent and protect the rights of 
the elderly population on an equal basis with other age categories. Governments and managers should ensure the right of older people to participate in public life, despite their natural physical limitations.

The third group of approaches -- consists of approaches, related to the analysis of the symbolic nature of old age in specific societies, and the peculiarities of the subcultures of older people. Despite the development of similar types of demographic structure in a number of countries around the world, each country has its own cultural characteristics. This is an important moment for solving the problems of society in the field of population aging. So, China is strongly influenced by Confucianism, so the concept of "Xiao" about honoring parents is still relevant. The hieroglyph 孝 of the oldest written form looks like a child, supporting an old man:

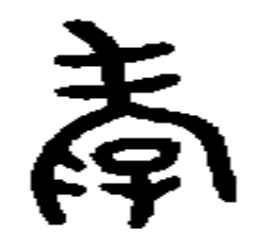

Fig. 1. Hieroglyph, used in the designation of the concept of Xiao

The modern spelling of this hieroglyph consists of two parts. The upper part -- The upper part is 老 ("the aged"), the lower part --, and the lower part is 子 ("the sons genertation"). This is the essence of this concept: the younger generation must support the oldergeneration. The principle of “老吾老，以及人之老" mentioned in Analects of Confucius "honoring not only one's older relatives but also others", encourages all members of society to take care of the elderly, regardless of whether the society is considered aging-respect is the basis in any case.

Also, the obligation to honor parents is enshrined at the legal level in the "Marriage Law" of China: "When children fail to meet their maintenance obligations, parents, who are unable to work or live in difficult conditions, have the right to demand alimony payments from their children. Those, who refuse to pay them, may be required to do so in court, and in case of non-compliance with the requirements, they must be brought to criminal responsibility in accordance with the law." Paragraph 261 of the Criminal Code clearly states, that " 


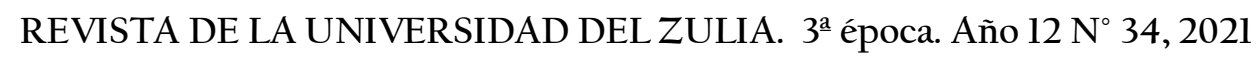

Li Zhongyuan // Social policy of Russia and China: a comparative analysis... 282-296

DOI: http://dx.doi.org/10.46925//rdluz.34.17

if the younger generation does not fulfill their responsibilities for the maintenance and material support of their parents, then violators of this instruction may face imprisonment for up to five years or criminal liability"" From this, we can conclude, that in the case of China, it would be more reasonable, and culturally and historically logical to solve the problems, caused by changes in the age structure, not only by the state, but also by society as a wholethis is already an attitude, that needs state assistance.

In Russia, older people have historically also been a source of wisdom, informal power, and special social status. However, this was not fixed in legal or ideological documents, and the main manifestation of honoring a person for his age can be considered events, related to the Great Patriotic War. Most of the people, who now make up the category of the elderly, somehow faced the war directly or through overcoming its consequences, so the special status of an elderly person in Russia today is associated with the degree of their proximity to the events of those years. Beyond that, an elderly person in Russia is basically a legal status.

It should be noted, here that in the research literature there is a position, according to which older people are not an economic or purely-age group, but a subculture, that is, the research emphasis is placed on the primacy of the social nature of the division of people into the elderly and those, who have not yet reached the elderly status. According to the approaches of this category, older people-use their free time differently, and show different levels of activity. Experts of the World Health Organization also analyze the social activity of older generations along with the demographic and economic characteristics of this population group. Social activity is the conditions and opportunities (health, safety) for maintaining the quality of life through continued participation in society not only in the labor market, but also in the social, cultural, spiritual, and civil life of society.

This approach indicates a possible definition of the elderly population as a group, united not only by age indicators, but also by behavioral characteristics. It is the aspect of common culture that creates relations between older citizens, while simultaneously separating them from others and connecting them with them, but still forming their own, special culture (Rose, 1962). Special norms and values are formed, as well as their own way of life. With age, a person loses the usual professional, official, often economic, and power statuses, and there is a need for a newone, which is based precisely on age, since public communication with other groups is limited. The analysis of older people as a subculture allows us to analyze 


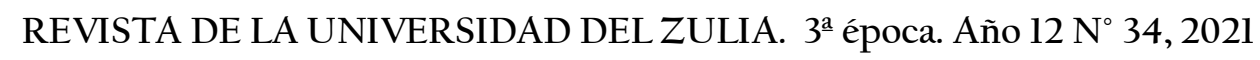

Li Zhongyuan // Social policy of Russia and China: a comparative analysis... 282-296

DOI: http://dx.doi.org/10.46925//rdluz.34.17

the formation of ethical ties, ways to adapt to changes in the level of health and social inclusion. It is adaptation that becomes the most essential mechanism for the subculture of older people (Alperovich, 1998).

The subcultural approach for Russia manifests itself precisely in defining the majority of older people as "veterans", that is, in reducing the complex full-fledged life stage to a number of cultural characteristics and manifestations. In China, in addition to traditional respect, the elderly have, a shortcut lovers of Square Dancing (a group dance in the square, people of different age classes in the evening voluntarily go on the streets, the squares dance), or their free time to search the second half for the younger members of the family -- and that, and another is a significant simplification, which affects the nature of the perception of the elderly population.

However, a comparison of theoretical approaches cannot provide complete information about, the principles on which social policy in the field of the elderly population is based in modern Russia and China. To form such an understanding, it is necessary to turn to the motivation of those, whose forces and decisions implement social policy.

2. Results of expert interviews: Potential exchange of experience in the field of social policy

Were selected using the "snowball" method. It was based on social security experts, who shared the contacts of their colleagues, who could provide answers to the interview questions. The study included 13 interviews with a total duration of 7 hours and 26 minutes. Interviews were conducted starting from 01 August 012020, 2020. until 02 February 022021, 2021. Thus, it was possible to record the current state of social policy in relation to the elderly population. 6 interviews were conducted among Chinese respondents, and 7 interviews were conducted among Russian respondents.

Experts interviewed, both Russian, and Chinese, expressed the opinion, that the aging of the population is more of a social, problem than an economicone. Despite the fact, that the aging of the population creates a direct (pension) and indirect burden on the state budget ("reducing the labor force creates big problems for the economy" - this phrase was heard by both Chinese, and Russian respondents), the aspect of public relations concerns experts more. Thus, one of the 


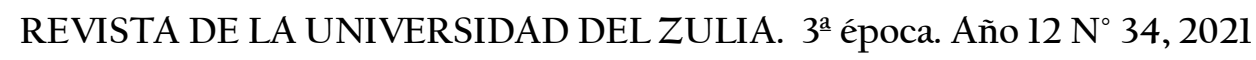

Li Zhongyuan // Social policy of Russia and China: a comparative analysis... 282-296

DOI: http://dx.doi.org/10.46925//rdluz.34.17

Chinese respondents points to the emerging "conflict between traditional and modern culture" of interaction and mutual assistance between generations, which is connected with the complex nature of modern old age, which goes beyond family relations. Several Chinese experts, answering the question about the General characteristics of the situation of the elderly population in the country, made reference to population policy and its role in the current situation of the elderly person: "to change the policy of family planning has led to serious disruptions in the social structure", and the consequences of these violations can be so significant, that "the government will have to seek additional means of solving this problem".

Despite the suggestion to describe the elderly population as a social, group rather than an economic one, both Russian and Chinese experts focused on economic perception. Russian experts first of all drew attention to the lack of characteristics in older people, that would make them economically "beneficial" to society. And Chinese experts believe, that it is necessary to develop the consumer market for older generations. As pointed out by the respondents, an elderly man -- is primarily for physically disabled people ("not able to work because of the nature of health", "physical health weakened day by day" - a Chinese expert social welfare of the city), as well as people, are subject to risks in the field of employment ("at work, many older people are the so-called ageism, they are forced to reduce their working hours or quit", "when you lose your job, you can only rely on the state or the family" - the opinion of the Russian respondents, scientific expert on dealing with the promotion of cooperation between Russia and China). Another characteristic of the social group of the elderly population, which is singled out by both Russian, and Chinese experts, is a special psychological state, "a sense of uselessness, professional lack of demand, dependence on the younger generation", "the most difficult thing is loneliness, lack of support, separation from society".

Experts from Russia and China gave slightly different answers to the question of which social institution should be focused on working with the vulnerable category of the elderly population. Thus, Russian respondents emphasized the impossibility of solving these 


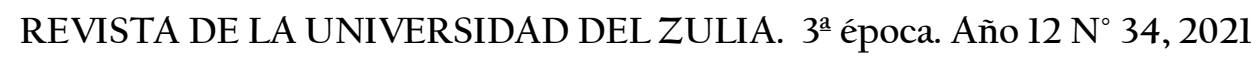

Li Zhongyuan // Social policy of Russia and China: a comparative analysis... 282-296

DOI: http://dx.doi.org/10.46925//rdluz.34.17

problems without family participation, since "in Russia, pension payments are often insufficient to meet the basic needs of the aging population". Chinese experts, contrary to the theoretically assumed emphasis on the traditional values of Confucianism (respect for elders, support for their younger generations), stressed, that the family can only be supported, where there is no state support, for example, in rural areas. As for the rest, according to the interviewed experts from China, it is the state that should maintain a leading role in this issue through the creation of "guidelines", that guide local government bodies. For additional question, is whether the holding of the state social policy Department of elderly from the "active" population, experts from both countries objected, that there are "objective health indicators in most cases distinguish seniors from young people", that is, if separation occurs, it is not by reason of conducting public policy, and a deeper biological and relevant social causes.

This is also evidenced by the answers to questions about the role of cultural characteristics in social policy: many policy outcomes differ from those planned not so much because-of mistakes at the level of administrative implementation, but because of-the peculiarities of the institution of the family and the perception of a person's life path in a particular society. So, one of the Russian experts makes a direct referenceto this: "traditions within the family institution also differ, and these differences should be taken into account in the development of social policy". A similar idea is expressed by a respondent from China, who speaks of the need to work precisely through "promoting the idea" of the acceptability of alternative ways of caring for elderly relatives among the population, as opposed to the simple management measuresused. Such accents, as experts note, are not always present in the implemented support measures, which is mainly due to the uneven distribution of resources between the country's regions; in China, the differences are mainly between urban and rural areas, in Russia - between regional centers and "outskirts".

Thus, giving a general description of the situation of the elderly in the country, experts note a number of points. BoFirstпервых, the situation of the elderly population is really not a matter of economics, but of social relations. Solving the problems of an aging society and the consequences of an aging society require not only financial investments, but also social efforts, since an elderly person is a product of socialization, a part of society, and often social 


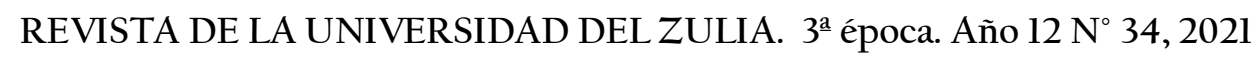

Li Zhongyuan // Social policy of Russia and China: a comparative analysis... 282-296

DOI: http://dx.doi.org/10.46925//rdluz.34.17

resources are more necessary for him, than materialones. Secondly, there is uncertainty about, which actor of public relations should be the main one in interactions with the elderly - neither the family, nor the state in both countries at the moment, according to the experts surveyed, can not cope with their obligations towards the elderly. For both countries, it is important to instill the values of responsibility and care in family members, who have to take care of elderly relatives or who have already faced this task, however, the current context of public relations in both Russia, and China makes it difficult to ensure a problem-free old age.

When asked about the effectiveness of current measures, both Russian, and Chinese experts did not give a direct answer, saying no longer, which of the existing social policy measures is effective, but rather, what measures are possible and would be effective, if they were implemented in practice. Social policy, aimed at the elderly population, is initially seen by Russian and Chinese experts as ineffective, and requires further development. Speaking about potentially-effective measures, Russian experts emphasized the need to expand opportunities to preserve the status of an elderly person as economically-active through employment and retraining, and a similar idea is expressed among Chinese respondents, who suggest using new technologies, to "partially solve the problem of labor shortage" due to retirement of an elderly person. Unlike the Russian respondents, Chinese experts see potential pension as one of the measures of social policy to maintain the living standards of older, regardless of, whether they work or not, that confirms the special status of the state initiative, who is credited with the Chinese experts implemented measures; in their view, without the participation of the state social policy is impossible.

The answers to questions about effective and ineffective measures show, that experts tend to "look for those responsible" for inefficiency, rather than delve into the essence of specific measures and evaluate them in detail. So, one of the Russian experts said, that "in Moscow and major cities the situation is in this respect better, than in small towns", that is, the effectiveness of the measures associated not with their content and implementation mechanisms, and with the traditional view that, in the regions life is more complicated, less economically successful, and so on. Such an opinion contradicts the, way social policy measures are actually implemented: regulations and initiatives, implemented locally, are essentially, the same for all localities and are aimed at solving urgent problems of the local population, regardless of the 


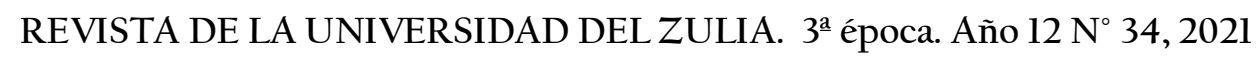

Li Zhongyuan // Social policy of Russia and China: a comparative analysis... 282-296

DOI: http://dx.doi.org/10.46925//rdluz.34.17

size and number of the population. Among Chinese respondents, performance ratings are less tied to such thinking patterns: according to one of them, all social policies "help solve problems, but the extent, to which they can solve problems, varies".

Questions about specific measures and ways to improve them were left unanswered or widely commented on by almost all the experts interviewed. This can be attributed to the style of their responses to questions about the effectiveness of social policies in general, which showed, that the perception of effectiveness was more related to the usual ideas about the problems of older people, than was a manifestation of expert evaluation of specific measures. Chinese respondents did not provide meaningful answers to questions about potential new measures and the possible new role of the family in social policy. In addition, experts from China did not elaborate on the question of, how to better integrate an elderly person into public life. It can be assumed, that these questions seemed superfluous to experts, not providing new information to the answers, that experts gave earlier, since in China traditionally the family plays a significant role in working with the elderly, and the society, which already consists of a large proportion of the elderly population, has been integrating the elderly for many years.

Russian experts expressed the opinion, that the state should play a more active "ally" of the family in social policy: the role of the family - "to integrate the older members in daily life, contribute to their comfortable psychological state, that older people do not feel unnecessary", and the task of the state "to implement the measures, which are within its competence (the creation of leisure centres, providing high-quality and free medical care, providing resort-sanatorium vouchers at discounted and affordable prices, the increase in pension payments)". At the same time, experts see the development of information technologies, which, among other things, could help reduce discrimination in the workplace based on age, as one of the means of integrating an elderly person into active social life.

Summing up the analysis of Block 2, we conclude, that a contradiction was found in the course of expert interviews. Despite the fact, that the expert has special professional knowledge, and works in the field of implementing social policy measures, he often does not perceive politics as a set of more or less effective practices, but rather looks at it as a somewhat abstract array of measures of state influence on society. The responses of experts from 
REVISTA DE LA UNIVERSIDAD DEL ZULIA. $3^{a}$ época. Año $12 \mathrm{~N}^{\circ}$ 34, 2021

Li Zhongyuan // Social policy of Russia and China: a comparative analysis... 282-296

DOI: http://dx.doi.org/10.46925//rdluz.34.17

both Russia, and China to questions about effectiveness demonstrated that working in the field of social policy implementation does not always mean being interested in the details and features of this policy and having daily thoughts about ways to improve its effectiveness. Therefore, based on the experts responses, it can be assumed, that one of the sources of reduced effectiveness of the measures taken in both countries is the formal approach of people, involved in translating social policy measures from the field of state and legislative initiative to the field of local practice.

The responses, to the third block, of questions confirm the trend, identified in Block 2: experts are not inclined to think about, what measures can be effective. Russian experts were asked to evaluate the measures, implemented in China: legally oblige children to provide for their parents, create specialized committees on a voluntary basis, that represent the interests of older people in government bodies, and create specialized educational institutions for older people, where they could get new skills, and refresh their knowledge of the existing specialty. Russian experts expressed their agreement with the proposed measures, implemented in China, but the answers practically did not go beyond the expression of consent. The only additional comments, that were made, indicated the need for a "detailed study" of the measures, proposed for borrowing. The Chinese respondent was asked to consider three possible measures, implemented in Russia: payment of regular allowances for children up to their majority, nationwide thematic actions for older people, related to historical moments, with gratitude to older generations for their work, and regular state vouchers for treatment in sanatoriums or medical centers after a certain age. Chinese experts were laconic and pointed mainly to the financial aspect of moving measures from Russia to China: Russian measures, according to Chinese respondents, "require a lot of financial support" and "can be implemented on a pilot basis" In addition, experts from China found already existing alternatives for all the proposed measures, which indicates a tendency to adhere to the already existing course in social policy, even if the proposed new measures may be more effective.

The conducted interviews, therefore, allowed us to make not only an expert assessment of directly implemented social policy measures in Russia and China, but also to identify an acute management problem. This problem lies in the formality of the experts approach to social policy, the perception of it as a given, created by the state, and not as a set of initiatives, implemented by people for people. This approach seems to contradict the fact, that experts present the 
REVISTA DE LA UNIVERSIDAD DEL ZULIA. 3ª época. Año $12 \mathrm{~N}^{\circ}$ 34, 2021

Li Zhongyuan // Social policy of Russia and China: a comparative analysis... 282-296

DOI: http://dx.doi.org/10.46925//rdluz.34.17

elderly population as a social, rather than an economic group, and emphasize the special role of the family and the immediate environment in ensuring a problem-free old age.

Expert interviews complement the conclusions, drawn in the course of theoretical analysis and consideration of the essence of measures implemented in both countries. From the point of view of a theoretical view of the elderly population, it can be said, that the interviewed experts were more likely to support an economic approach to the problems of population aging, a more complex integral approach, which includes understanding the social image of the elderly person and its cultural characteristics, rather than a statistical and economic approach to the problems of population aging. Russian experts confirmed the division between the role of the state and the family in solving the problems of the elderly population revealed in the course of theoretical analysis. Chinese experts did not place such a strong emphasis on the economic independence of the elderly person, as it was assumed, based on the analysis of literature, research and cases.

The assumption, that social policy is less effective due to the perception of the elderly as an "inconvenient" group, that does not integrate into an economically active society, was also confirmed in expert interviews. The experts did say, that the measures taken should have as one of their goals the preservation of the participation of older people in the labor force, ignoring the characteristics of this group and its potential to transfer experience, values and perform alternative social roles and tasks.

A general conclusion, can be drawn that the problem is the lack of perception of the elderly population as a group with a special subcultural and symbolic content, there is an increase in the social distance between the elderly and the active population, and the problem of ensuring the needs of the elderly, both basic, and more complex, is acute. However, it is necessary to emphasize a fact, that is not obvious for theoretical analysis and is clearly manifested in the course of communication with experts: solving these problems and fulfilling the tasks of effective exchange of experience lies not only in changing the essence and mechanisms of the proposed social policy measures, but also in changing the approach to their implementation by managers themselves. The interviews showed a high degree of formality in the approach to social policy on the part of those, who should be most interested in its implementation and in improving its effectiveness. We can assume the reasons for this attitude of specialists: work in the 
REVISTA DE LA UNIVERSIDAD DEL ZULIA. 3ª época. Año 12 N 34, 2021

Li Zhongyuan // Social policy of Russia and China: a comparative analysis... 282-296

DOI: http://dx.doi.org/10.46925//rdluz.34.17

field of implementing social policy measures is often not highly paid and is perceived as a means of livelihood, and not as a means of solving public problems, which is true for both Russian, and Chinese civil servants, since they are part of a similar model of public service (Zhuravleva, 2017).

\section{Conclusion}

A sociological analysis of approaches to the study of social policy regarding the problem of population aging indicates, that social policy should be studied in its entirety. The low degree of understanding of the importance of the complexity of the issue of aging in society leads to the emergence of not only economic problems, which are manifested in the tax burden and the need to support the less economically-active population at the expense of those, who continue to work. Existing social policy measures do not fully take into account the importance of maintaining the inclusion of an elderly person in public life, and they do not work in any way with the values of the population.

However, this perception is more typical for Russia, than for China, which has a great potential for adapting successful measures, taken in China, to Russian realities. Such adaptation requires an understanding of the cultural contexts of social policyimplementation, so direct borrowing of China's experience is impossible. The potential for a comprehensive policy transformation lies, primarily, in the search for functional alternatives to values, that differ widely between countries. The differences are related to the degree of orientation to society in matters of support for old age, in the philosophical basis of policyimplementation, and in the degree of importance of legal facts relative to public facts.

Expert interviews have raised the question, that the degree of effectiveness of measures in both countries strongly depends on the attitude of managers to their role in implementing measures. According to the interviewed experts, the attitude is mostly formal, which affects the effectiveness of social policy in the field of the elderly population. From this it can be concluded, that the employment of social policies between China and Russia as a way of solving local problems will be effective, if people, involved in the implementation of these measures, will be more proactive, will receive financial compensation for his initiative, will have the opportunity to improve their professional skills social policy of the elderly population, expressed interest in efficiency. 
REVISTA DE LA UNIVERSIDAD DEL ZULIA. $3^{a}$ época. Año 12 N$^{\circ}$ 34, 2021

Li Zhongyuan // Social policy of Russia and China: a comparative analysis... 282-296

DOI: http://dx.doi.org/10.46925//rdluz.34.17

\section{References}

Alperovich V. D. (1998). Old aget: socio-philosophical analysis/ V. D. Alperovich. Rostov-onDon.: SKSC HSE.

Dobrokhleb V.G., Barsukov V.N. (2017). Demographic theories and the regional aspect of population aging. Economic and Social Changes: Facts, Trends, Forecast, 2017, No.6 (54). DOI:10.15838/esc.2017.6.54.6

Fadeeva T. A. (2018). Modern problems of migration interaction between Russia and China. Russia: Trends and Prospects of Development, 2018, No.13-1. CP. 208.

Galasso V., Profeta P. (2018). When the state mirrors the family: the design of pension systems // Journal of the European Economic Association. 2018. T. 16. №. 6. C.1749.

Guo M. (2007). A brief analysis of China's social policies to solve the problem of population aging // Population and economy. 2007. No. 1. pp. 112-113.

Ntugarten. A. (1968). Adult Personality: Toward a Psychology of the life Cycle / A. Ntugarten. Chicago.

Rose A.M. (1962). The Subculture of the Aging: a Topic for Sociological Research // The Gerontologist. 1962. №2. C. 123-127. DOI:10.1093/geront/2.3.123

Zayonchkovskaya Zh., Mkrtchyan N. (2007). Internal migration in Russia: legal practice / / Center for Migration Studies of the Institute of National Economic Forecasting of the Russian Academy of Sciences, Moscow.

Zhuravleva T.A. (2017). The system of remuneration and motivation of state civil servants: an overview of international practice. Public administration. Electronic Bulletin, 2017, No.64.

CP. 332-333. 